\title{
A Novel Coplanar Waveguide-Fed Compact Microstrip Antenna for Future 5G Applications
}

\author{
Mustafa Berkan Bicer
}

\begin{abstract}
In this study, a coplanar waveguide-fed compact microstrip antenna design for applications operating at higher $5 \mathrm{G}$ bands was proposed. The antenna with the compact size of $8 \times 12.2 \mathrm{~mm}^{2}$ on FR4 substrate, having the dielectric constant of 4.3 and the height of $1.55 \mathrm{~mm}$, was considered. The dimensions of the radiating patch and ground plane were optimized with the use of artificial cooperative search (ACS) algorithm to provide the desired return loss performance of the designed antenna. The performance analysis was done by using full-wave electromagnetic package programs based on the method of moment (MoM) and the finite integration technique (FIT). The $10 \mathrm{~dB}$ bandwidth for return loss results obtained with the use of the computation methods show that the proposed antenna performs well for $5 \mathrm{G}$ applications operating in the $24.25-27.50 \mathrm{GHz}, 26.50-$ $29.50 \mathrm{GHz}, 27.50-28.35 \mathrm{GHz}$ and $37-40 \mathrm{GHz}$ frequency bands.
\end{abstract}

Keywords: compact microstrip antenna; coplanar waveguide-fed; microstrip antenna design; planar antenna; $5 \mathrm{G}$ applications

\section{INTRODUCTION}

Recently, the rapid development of systems such as short-range communication, online music and video services, smart systems, health diagnostic and treatment devices, and the internet of things (IoT), which require high-quality voice, video and data access with high speed, has led researchers to research and develop fifth-generation (5G) mobile communication technologies $[1,2,11-19,3-10]$. It is foreseen that the need for mobile traffic in the coming years will be much higher than the amount needed today. 5G mobile communication technology enables high-speed data transfer covering wide areas and meets requirements such as high capacity, security, and reliability, allowing to reduce latency and power consumption. 5G technology, which is among the most important developments of recent years, is thought to provide development in many fields such as economic development, education, health, defense, transportation, and energy systems [1, 2, 11-19, 3-10]. Electronic devices such as refrigerators, air conditioners, ovens, air conditioners, and other digital services in daily use will become remotely manageable thanks to $5 \mathrm{G}$ technology. Since it has such a wide range of applications, the frequency spectrum to be allocated for $5 \mathrm{G}$ communication is of great importance. $5 \mathrm{G}$ is being conducted by various countries and companies in various ranges of frequency spectrum, such as sub-6 GHz spectrum covering $1.427 \mathrm{GHz}$ to $1.518 \mathrm{GHz}, 1.69$ $\mathrm{GHz}$ to $2.2 \mathrm{GHz}, 2.30 \mathrm{GHz}$ to $2.69 \mathrm{GHz}, 3.30 \mathrm{GHz}$ to 5.00 $\mathrm{GHz}$ bands and $24.25 \mathrm{GHz}$ to $27.50 \mathrm{GHz}, 26.50 \mathrm{GHz}$ to 29.50 $\mathrm{GHz}$ and $37.00 \mathrm{GHz}$ to $40.00 \mathrm{GHz}$ frequency bands. However, due to the low atmospheric absorption rate, it is thought that $5 \mathrm{G}$ applications will concentrate mostly on the Ka-band [1, 2, 11-19, 3-10].

Reductions in the size of abovementioned systems necessitate the development of millimeter-wave antennas having both high performance and smaller size [20-23]. Due to their impressive advantages such as low weight and volume, low production cost, small dimensions, planar structure, ease of design and manufacturing, and easy integration with solid-state circuits, microstrip antennas (MA) have been the focus of interest for researchers designing antennas for 5G applications. However, conventional shaped microstrip antennas with triangular, rectangular, and circular configuration have limitations such as low gain and narrow bandwidth. To overcome these limitations, the geometries of the microstrip antennas are modified in various ways to have characteristics such as high gain, wide bandwidth, and multiple resonance frequencies [20-23]. One of the methods used to increase bandwidth is to change the feeding structure of the antenna. Coaxial-fed microstrip antennas have a very narrow bandwidth, whereas coplanar waveguide-fed (CPW) microstrip antennas have a broad bandwidth. In order to provide multiple frequency band performance, making modifications on the radiation geometry and ground plane of the antenna is widely preferred in antenna design. The microstrip antennas obtained by making modifications on the geometries of conventionalshaped antennas are called as compact microstrip antennas (CMA). The analysis of CMAs is complicated due to the complexity of their structures, and computer-aided full-wave electromagnetic computation software based on the techniques, such as finite element method (FEM), finite integration method (FIT), finite difference time domain (FDTD) and method of moments (MoM), is needed to perform the required calculations [24-26]. The performance of microstrip antennas operating at high frequencies is severely affected by the change in physical dimensions. Therefore, artificial intelligence optimization techniques are used in the design of antennas that can meet the desired performance criteria. In the literature, there are studies related to CMA design using optimization techniques such as artificial bee colony (ABC) [23, 27-29], ant colony optimization (ACO) [30-32], differential evolution (DE) [3335], genetic algorithm (GA) [30, 31, 34, 35] and particle swarm optimization (PSO) [34, 35]. Jian et al. [36] designed an antenna using a hybrid optimization algorithm, particle swarm ant colony optimization (PSACO) algorithm, operating at the center frequency of $28 \mathrm{GHz}$. They verified the reliability of the PSACO that they used to optimize the antenna's dimensions with the use of Elman Neural Network (ENN) model. Akdagli and Ustun [37] designed a microstripfed rectangular microstrip antenna with a modified ground 
plane using the new hybrid optimization algorithm that they proposed using the $\mathrm{ABC}$ and $\mathrm{DE}$ algorithms. The outer dimensions of the proposed antennas vary between $19.20 \times$ $16 \mathrm{~mm}^{2}$ and $62.21 \times 51.90 \mathrm{~mm}^{2}$. In another study of Jian et al. [38], a millimeter-wave antenna was designed using a new hybrid optimization algorithm with the imperial competition algorithm (ICA) and ant colony algorithm (ACO), operating at a frequency of $28.5 \mathrm{GHz}$.

This paper aims to propose a coplanar-wave guide (CPW) fed compact microstrip antenna for future $5 \mathrm{G}$ applications. The designed antenna has a low profile with the volume of $8 \times 12.2 \times 1.55 \mathrm{~mm}^{3}$ and operating between 24.14 $\mathrm{GHz}-32.40 \mathrm{GHz}$ and after the $33.72 \mathrm{GHz}$. To achieve the best performance characteristics for $5 \mathrm{G}$ applications, the optimization process of the proposed antenna dimensions is performed using the ACS algorithm, and the FIT technique is utilized for the simulation and performance analysis of the antenna. The obtained antenna has compact dimensions and can be used for mobile applications.

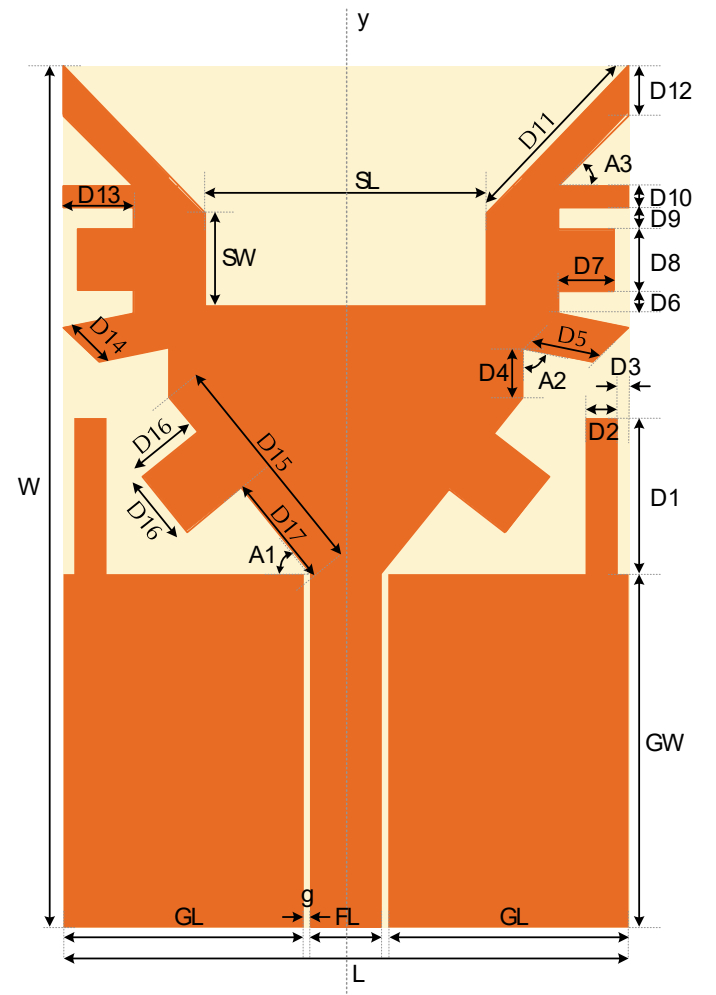

Figure 1 Top view of the proposed antenna

\section{ANTENNA DESIGN}

The presented antenna for $5 \mathrm{G}$ applications, operating in the range of the $24.25-27.50 \mathrm{GHz}, 26.50-29.50 \mathrm{GHz}$, $27.50-28.35 \mathrm{GHz}$, and $37-40 \mathrm{GHz}$ frequency bands, is shown in Fig. 1. As shown in the figure, the antenna has symmetrical radiating branches on both sides of the trapezoidal radiating patch, and both ground planes modified by adding thin rectangular elements. The proposed antenna is fed with a $50 \Omega$ SMA connector. Initially, the sizes of the radiating arms determined considering the wavelengths of each frequency. Subsequently, the dimensions are optimized to give the desired performance criteria related to $10 \mathrm{~dB}$ bandwidth for return loss.

The values of the physical parameters of the antenna, shown in Fig. 1, are given in Tab. 1.

Table 1 Physical dimensions of the proposed antenna (in $\mathrm{mm}$ )

\begin{tabular}{|c|c|c|c|c|c|c|c|c|}
\hline D1 & D2 & D3 & D4 & D5 & D6 & D7 & D8 & D9 \\
\hline 2.21 & 0.44 & 0.16 & 0.70 & 1.02 & 0.31 & 0.81 & 0.87 & 0.31 \\
\hline D10 & D11 & D12 & D13 & D14 & D15 & D16 & D17 & L \\
\hline 0.30 & 2.89 & 0.70 & 1.00 & 0.71 & 3.20 & 1.00 & 1.57 & 8.00 \\
\hline W & GL & GW & SL & SW & g & A1 & A2 & A3 \\
\hline 12.20 & 3.40 & 5.00 & 4.00 & 1.31 & 0.10 & $51.34^{\circ}$ & $78.69^{\circ}$ & $45.00^{\circ}$ \\
\hline
\end{tabular}

A coplanar waveguide feeding structure is used to feed the designed antenna. The lengths of the microstrip feeding line and the ground planes are $1 \mathrm{~mm}$ and $3.4 \mathrm{~mm}$, respectively, while the widths of both ground planes and microstrip line are $5 \mathrm{~mm}$. The length of the gap between the microstrip line and the ground planes is taken as $0.1 \mathrm{~mm}$. The radiating patch, microstrip line, and ground planes are placed on the top side of the FR4 substrate having the dielectric constant of 4.3 , the height of $1.55 \mathrm{~mm}$ and the loss tangent of 0.02 . The antenna is entirely symmetrical concerning the $y$ axis.

\section{ANTENNA OPTIMIZATION}

The resonance frequency for an antenna operating at $\mathrm{TM}_{\mathrm{mn}}$ mode is given by Eq. (1) [39].

$$
f=\frac{c}{2 \sqrt{\varepsilon_{\mathrm{eff}}}} \sqrt{\left(\frac{m}{L}\right)^{2}+\left(\frac{n}{W}\right)^{2}}
$$

In Eq. (1), $f, c, \varepsilon_{\text {eff }}, L$ and $W$ parameters represent the resonant frequency of the antenna, effective dielectric constant, length of the antenna and width of the antenna, respectively, while $m$ and $n$ parameters represent the operating mode of the antenna. The effective dielectric constant value in Eq. (1) is calculated by the formula given in Eq. (2) [39, 40].

$\varepsilon_{\text {eff }}=\frac{\varepsilon_{\mathrm{r}}+1}{2}+\frac{\varepsilon_{\mathrm{r}}-1}{2} \sqrt{1+12 \frac{h}{W}}$

where $\varepsilon r$ and $h$ represent the dielectric constant value of the substrate and the height of the substrate, respectively. As seen in Eq. (1) and (2), the operating frequency of an antenna mainly depends on the dielectric constant of the material and the physical dimensions of the radiating patch. Since the height of the substrates that can be used to fabricate the antenna is standard, the dimensions of the antenna elements should be optimized to achieve the desired bandwidth characteristic. The bandwidth characteristic of an antenna is determined by the return loss graph, which is generated by calculating the formula given by Eq. (3) for each frequency [39]. 


$$
R L=-20 \log \left(\frac{z_{L}-z_{0}}{z_{L}+z_{0}}\right)
$$

where $z_{L}$ and $z_{0}$ represent the characteristic impedance of the antenna and the free space, respectively. As given in Eq. (3), the return loss represents the degree to which the antenna impedance is in agreement with the free space impedance. In this study, since the antenna is fed through a single port, the return loss value is considered only for $S_{11}$. In order to say that the designed antenna performs well in the desired frequency band, the bandwidth characteristic of the antenna should be below $-10 \mathrm{~dB}$ reference level. Accordingly, the cost function for the desired performance should be set so that the parameter $S_{11}$ is below $-10 \mathrm{~dB}$. The cost function used in the optimization process of the proposed antenna is given in Eq. (4).

$$
\begin{aligned}
& C F=\frac{1}{N} \sum_{n=1}^{N} C\left(f_{n}\right) \\
& C=\left\{\begin{array}{rr}
0, & S_{11, \text { calculated }}<S_{11, \text { desired }} \\
\left|S_{11, \text { desired }}-S_{11, \text { calculated }}\right|, & \text { otherwise }
\end{array}\right.
\end{aligned}
$$

The $C$ conditional cost term, used in Eq. (4), is given in Eq. (5). $N, S_{11 \text {, calculated }}$ and $S_{11 \text {, desired parameters represent the count }}$ of the desired frequency points, calculated $S_{11}$ parameters obtained with the help of the computational methods and desired $S_{11}$ values, respectively.

\section{ARTIFICIAL COOPERATIVE SEARCH ALGORITHM FOR DIMENSION OPTIMIZATION}

Artificial Cooperative Search (ACS) is a swarm-based optimization method that depends on the movement of two biologically interacting artificial superorganisms to obtain the global minimum value of the real-valued numerical optimization problem [41]. The amount of food that can be obtained from a particular region in nature is susceptible to seasonal climate changes. Due to this, some of the superorganisms migrate seasonally between different feeding regions. Superorganisms with such migration behavior are capable of moving from a living habitat with a decrease in the quantity and diversity of reserves it offers to a more fertile environment. In most species, the large number of members coalesce to form a superorganism before journey. Then, the more productive regions of the superorganism begin to migrate. Before migration, superorganisms can be divided into sub-superorganisms. Under these conditions, the coordination of the sub-superorganisms determines the behavior of the superorganisms [41].

In the ACS method, a superorganism, which consists of arbitrary solutions to the dilemma, corresponds to an artificial superorganism that migrates to further efficient nutrition spaces. The ACS method is form on two superorganisms defined as $\alpha$ and $\beta$, which are artificial subsuperorganisms equal to the size of the community, $N$. These sub-superorganisms hold as many individuals as the size of the problem, $D$. In the ACS, artificial sub-superorganisms, Predator and Prey, are detected using $\alpha$ and $\beta$ superorganisms. Predator sub-superorganisms in the method can track Prey sub-superorganisms for some time while migrating to the global minimum level [41].

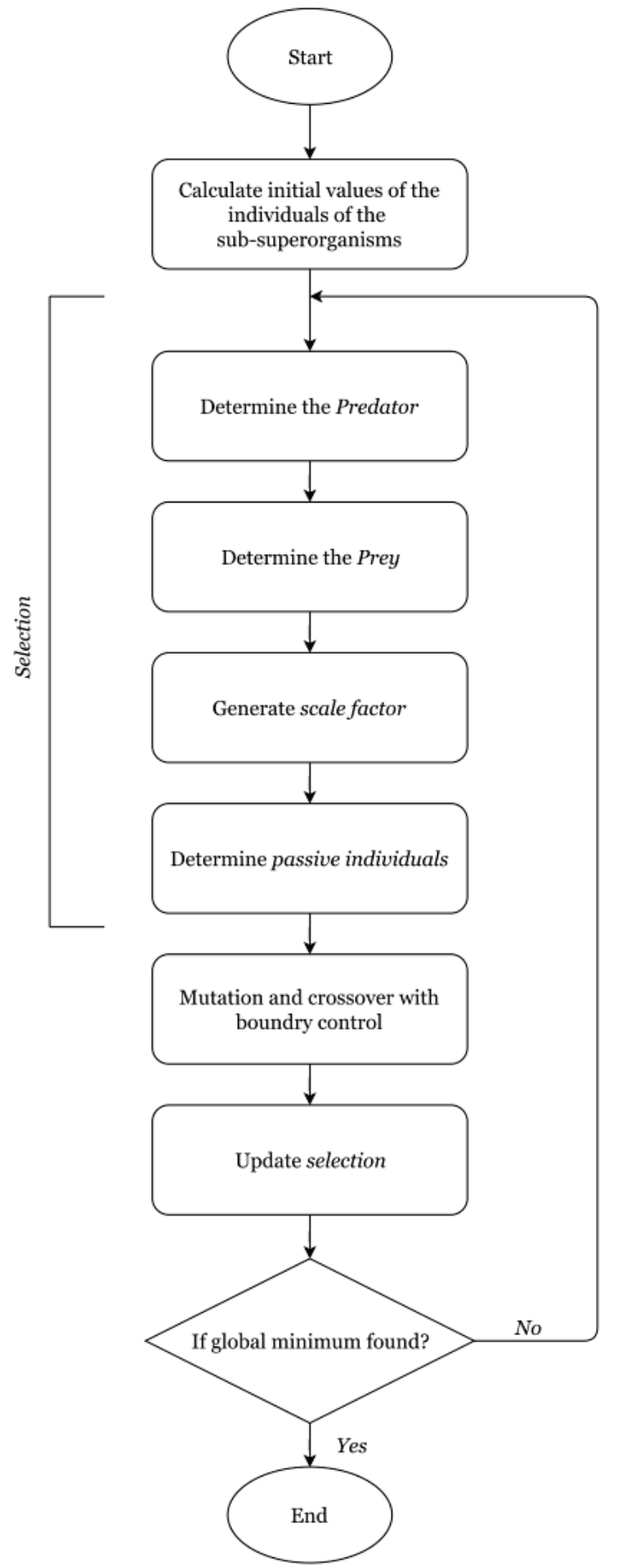

Figure 2 The flowchart of the ACS algorithm

The individuals of $i^{\text {th }}$ sub-superorganism of the two superorganisms take the values determined by the Eq. (6) and (7) as initial values. 
$\alpha_{i, j, g}=r n d \cdot\left(u p_{j}-\right.$ low $\left._{j}\right)+$ low $_{j}$

$\beta_{i, j, g}=r n d \cdot\left(u p_{j}-\right.$ low $\left._{j}\right)+$ low $_{j}$

where $i=1,2, \ldots, N$ and $j=1,2, \ldots, D$ while $g=0,1,2, \ldots$, maxcycle. The variable $g$ stands for the iteration number, called coevolution, and rnd is the random number chosen from the uniform distribution in the range of [0 1]. The upper and lower limits of the $j^{\text {th }}$ dimension are defined by the variables of $u p_{j}$ and $l o w_{j}$.

The fitness values calculated by the sub-superorganisms are given by Eq. (8) and (9).

$$
\begin{aligned}
& y_{i, \alpha}=f\left(\alpha_{i}\right) \\
& y_{i, \beta}=f\left(\beta_{i}\right)
\end{aligned}
$$

Since this study is on antenna design and optimization, the rest of the algorithm is given in Fig. 2 with the flowchart. Detailed information about the algorithm is available in the literature [41].

\section{NUMERICAL RESULTS}

The antenna dimensions are optimized by the help of artificial cooperative search (ACS) algorithm. The computations related to the antenna, which is designed according to the obtained dimensions, were made by the fullwave electromagnetic solvers based on the moment method $(\mathrm{MoM})$ and finite integration technique (FIT). The return loss curves of the designed antenna are shown in Fig. 3.

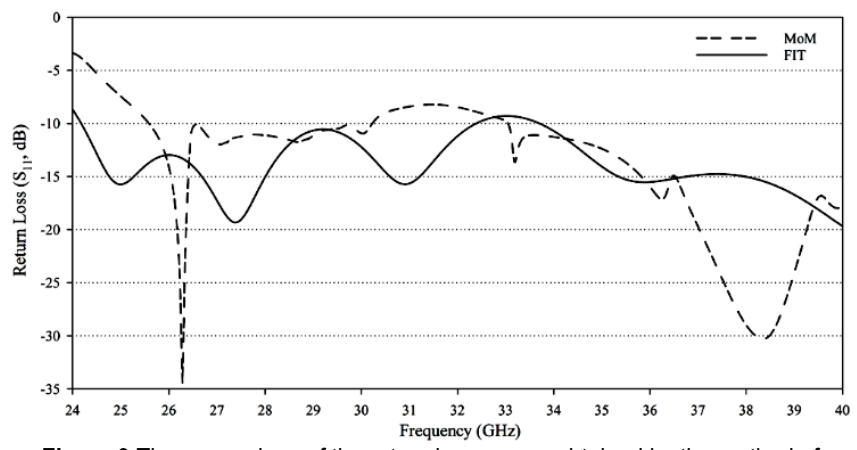

Figure 3 The comparison of the return loss curves obtained by the method of moments (MoM) and finite integration technique (FIT)

As can be seen from the figure, the return loss of the designed antenna is actually below the resonance reference value of $-3 \mathrm{~dB}$, where more than half of the incident power is radiated, throughout the desired frequency band. However, the radiation of more than $90 \%$ of the indicated power shows that the antenna performs well. According to the return loss result obtained by the MoM, it can be said that the antenna performs well in the range of $25.58 \mathrm{GHz}-30.24 \mathrm{GHz}$ and after the $33.04 \mathrm{GHz}$ frequency. In the frequency band up to $25.58 \mathrm{GHz}$, the antenna operates but cannot provide the higher performance. When the return loss values obtained by the FIT technique are considered, it can be said that the antenna performs well between the $24.14 \mathrm{GHz}-32.40 \mathrm{GHz}$ range and after the $33.72 \mathrm{GHz}$ frequency. Although there are discrepancies between the return loss results obtained by two methods around the frequency of $24 \mathrm{GHz}$, the curves are in a good agreement with each other approximately $26 \mathrm{GHz}$ and later. Although most of the existing substrates perform well for the applications operating under the $10 \mathrm{GHz}$ frequency, they experience performance degradation for the mm-wave band due to dielectric loss and dispersion. In this sense, the performance loss can be experienced for inadequate quality FR4 substrate. The radiated power ratio curves are given in Fig. 4.

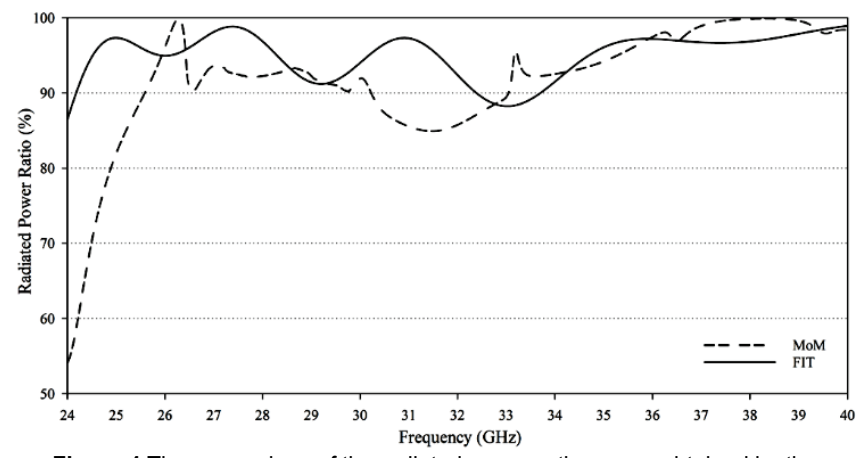

Figure 4 The comparison of the radiated power ratio curves obtained by the method of moments (MoM) and finite integration technique (FIT)

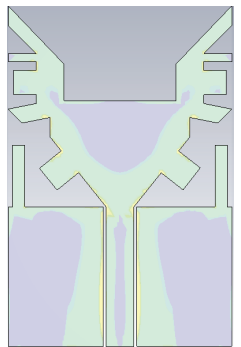

(a)

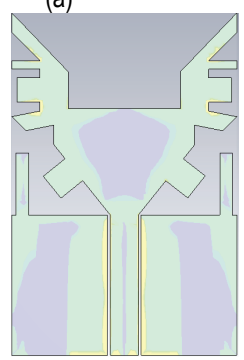

(d)

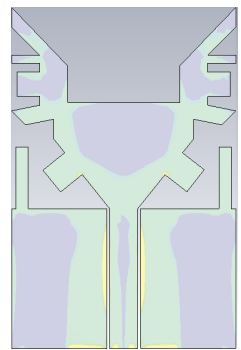

(b)

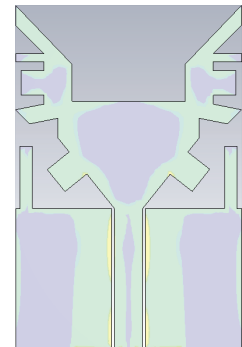

(c)
Figure 5 The surface currents of the designed antenna for (a) $24 \mathrm{GHz}$, (b) $28 \mathrm{GHz}$, (c) $32 \mathrm{GHz}$, (d) $36 \mathrm{GHz}$ and (e) $40 \mathrm{GHz}$

As it is seen from the radiated power curve obtained from the MoM, approximately $54.14 \%$ of the incident power is radiated at the $24 \mathrm{GHz}$ frequency, and $57.40 \%$ of the incident power is radiated at the $24.15 \mathrm{GHz}$ frequency. However, it is seen from the figure that more than $80 \%$ of the incident power is radiated to the air. According to the FIT, approximately $86.52 \%$ and $89.71 \%$ of the incident power are radiated at the $24 \mathrm{GHz}$ and $24.15 \mathrm{GHz}$ frequencies, respectively. The curve shows that the designed antenna radiates more than $90 \%$ of the incident power throughout the desired frequency band. 


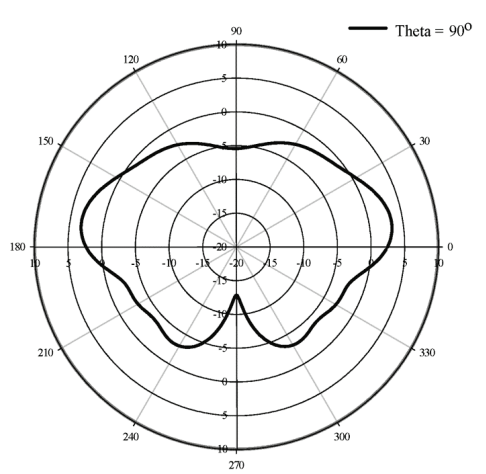

(a)

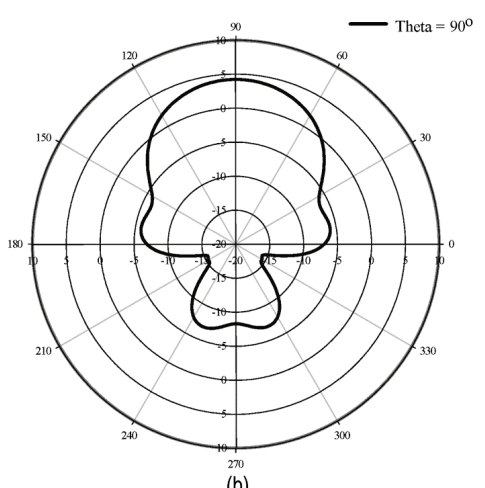

(b)

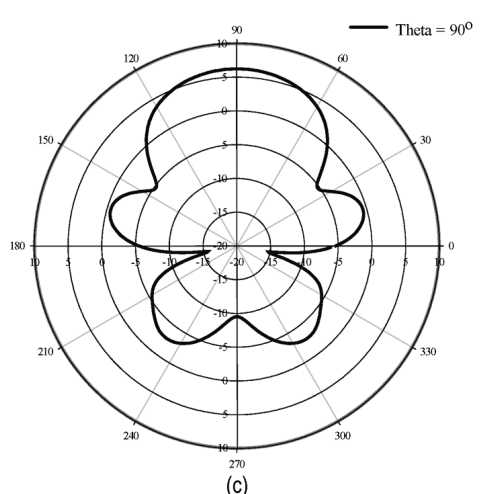

(c)
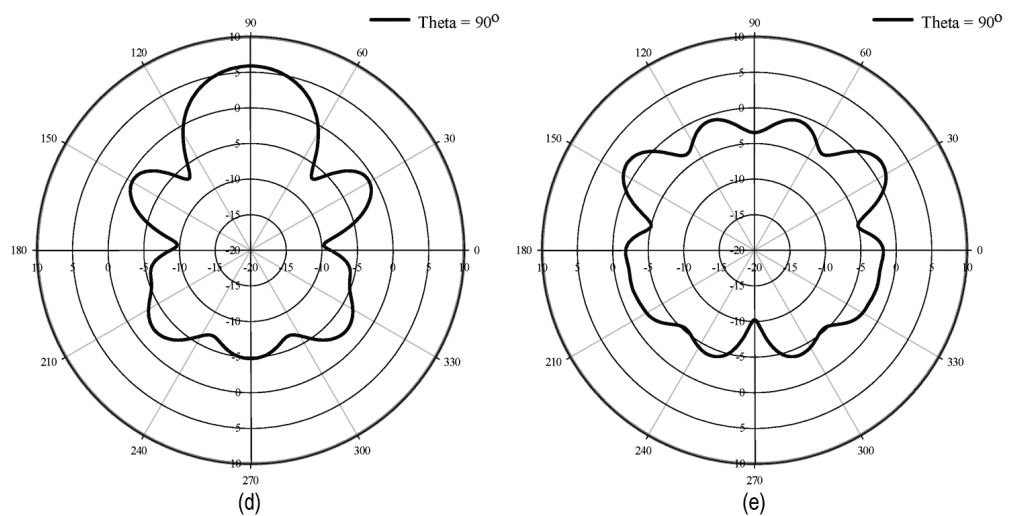

Figure 6 The simulated radiation patterns of the designed antenna for azimuth, $\theta=90^{\circ}$, at (a) $24 \mathrm{GHz}$, (b) $28 \mathrm{GHz}$, (c) $32 \mathrm{GHz}$, (d) $36 \mathrm{GHz}$ and (e) $40 \mathrm{GHz}$ frequencies
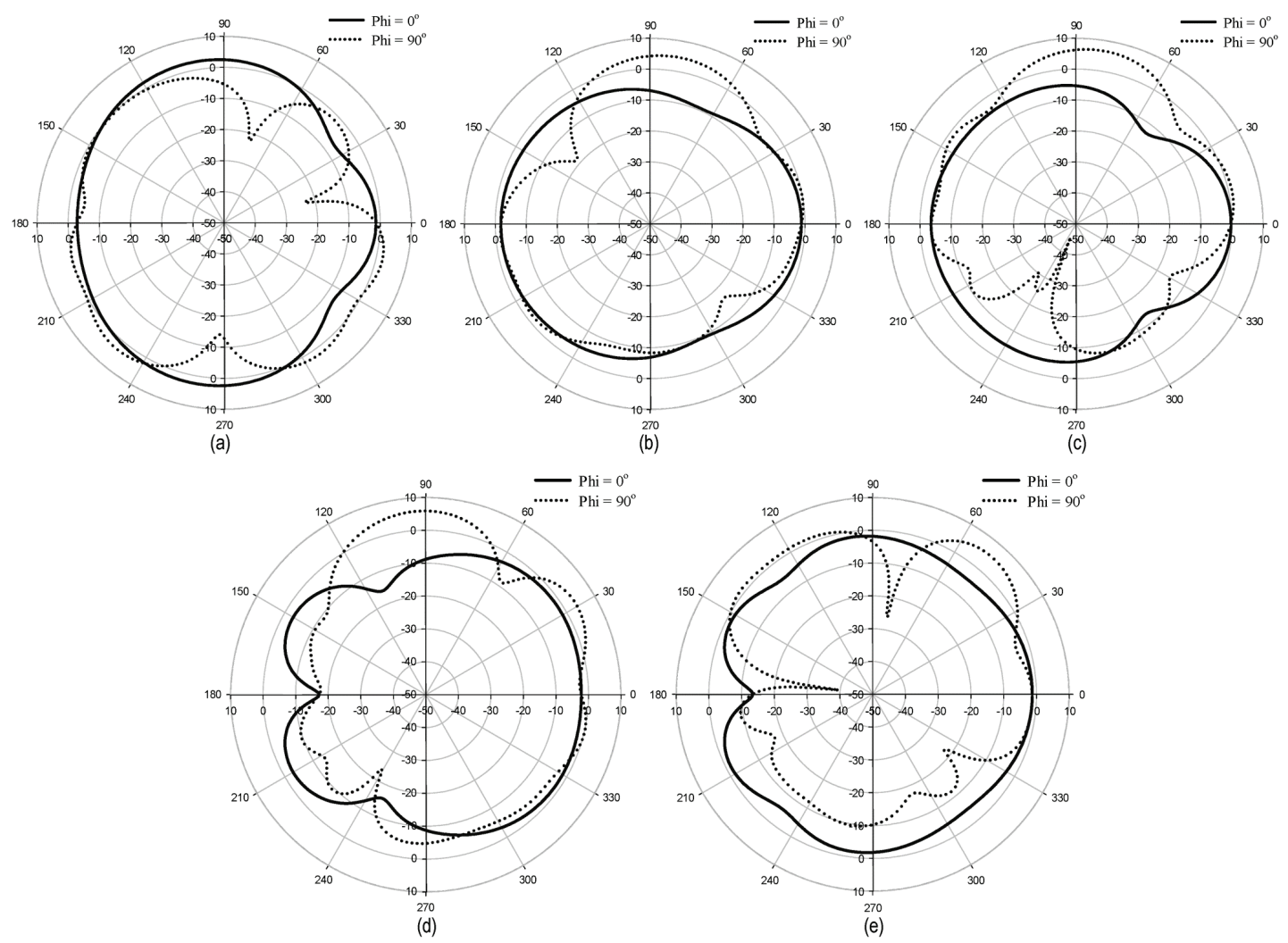

Figure 7 The simulated radiation patterns of the designed antenna for elevation, $\phi=0^{\circ}$ (solid) and $\phi=90^{\circ}$ (dotted), at (a) $24 \mathrm{GHz}$, (b) $28 \mathrm{GHz}$, (c) $32 \mathrm{GHz}$, (d) $36 \mathrm{GHz}$ and (e) $40 \mathrm{GHz}$ frequencies 
The figures of the surface currents of the proposed antenna at five frequencies between $24 \mathrm{GHz}$ and $40 \mathrm{GHz}$ are given in Fig. 5.

As can be seen from the figure, surface currents are concentrated at the edges of the radiating patch and the ground planes. The frequencies provided by the arms of the radiating patch can be seen from Fig. 5(a) - 5(e). Also, simulation studies have been carried out on the radiation patterns of the designed antenna. The radiation patterns obtained by simulations are shown in Fig. 6 and Fig. 7. The azimuth plane radiation patterns for five different frequencies in the range of $24 \mathrm{GHz}$ to $40 \mathrm{GHz}$ at $\theta=90^{\circ}$ are given in Fig. 6.

The radiation patterns for the azimuth plane of the designed antenna have a weakened shape from the back and sides, as seen from Fig. 6 . The radiation is weaker at $270^{\circ}$ for $24 \mathrm{GHz}, 210^{\circ}$ and $330^{\circ}$ at $28 \mathrm{GHz}, 191^{\circ}$ and $348^{\circ}$ at $32 \mathrm{GHz}$, and $270^{\circ}$ at $40 \mathrm{GHz}$ frequency but the radiation at almost all frequencies is higher at $90^{\circ}$ direction.

Unlike the azimuth plane, the radiation patterns of the proposed antenna for the elevation plane shows almost omnidirectional antenna characteristics, as can be seen from Fig. 7(a)-(e).

\section{CONCLUSION}

A novel coplanar waveguide-fed compact microstrip antenna for future $5 \mathrm{G}$ applications is presented. The proposed antenna design easily achieves the broadband performance required for $5 \mathrm{G}$ applications between $24 \mathrm{GHz}$ and $40 \mathrm{GHz}$ frequencies. The antenna with the compact size of $8 \times 12.2$ $\mathrm{mm}^{2}$ on FR4 substrate, having the dielectric constant of 4.3 and the height of $1.55 \mathrm{~mm}$, is considered. Afterward, the dimensions of the radiating patch and ground plane are optimized using artificial cooperative search (ACS) algorithm to provide the desired $10 \mathrm{~dB}$ bandwidth performance. The results obtained by performing separate simulations of the optimized antenna based on two different methods show that the characteristics of the antenna meet the desired performance criteria. The proposed antenna is thought to be beneficial for patch antenna designers and researchers. The optimized antenna can be fabricated simply by anyone.

\section{REFERENCES}

[1] Kaeib, A. F., Shebani, N. M., \& Zarek, A. R. (2019). Design and Analysis of a Slotted Microstrip Antenna for 5G Communication Networks at $28 \mathrm{GHz}$. 19 $9^{\text {th }}$ Int. Conf. Sci. Tech. Autom. Control Comput. Eng. STA 2019, 648-653. https://doi.org/10.1109/STA.2019.8717292

[2] Rahayu, Y. \& Hidayat, M. I. (2018). Design of $28 / 38 \mathrm{GHz}$ Dual-Band Triangular-Shaped Slot Microstrip Antenna Array for 5G Applications. $2^{\text {nd }}$ Int. Conf. Telemat. Futur. Gener. Networks, TAFGEN 2018, 93-97. https://doi.org/10.1109/TAFGEN.2018.8580487

[3] Oladapo, J. A., Yunusa, Z., Shuaibu, D. S., \& Hamidon, M. N. (2018). E-band slotted microstip patch antenna array for $5 \mathrm{G}$ broadband applications. $2^{\text {nd }}$ Int. Conf. Telemat. Futur. Gener. Networks, TAFGEN 2018, 121-124.
https://doi.org/10.1109/TAFGEN.2018.8580485

[4] Saini, M., Singh, S., Rai, A. K., \& Goel, T. (2018). Novel CPW-fed UWB Monopole Patch Antenna for 5G Mobile Technology. 14 $4^{\text {th }}$ IEEE India Counc. Int. Conf. INDICON 2017, 1-5. https://doi.org/10.1109/INDICON.2017.8487615

[5] Jilani, S. F., Abbasi, Q. H., \& Alomainy, A. (2018). InkjetPrinted Millimetre-Wave PET-Based Flexible Antenna for 5G Wireless Applications. 2018 IEEE MTT-S Int. Microw. Work. Ser. 5G Hardw. Syst. Technol. IMWS-5G 2018, vol. 1, 1-3. https://doi.org/10.1109/IMWS-5G.2018.8484603

[6] Subramanian, S., Selvaperumal, S. K., Thangasamy, V., \& Nataraj, C. (2018). Modified triple band microstrip patch antenna for higher 5G bands. Proc. $4^{\text {th }}$ IEEE Int. Conf. Adv. Electr. Electron. Information, Commun. Bio-Informatics, AEEICB 2018, no. 2015, 1-5. https://doi.org/10.1109/AEEICB.2018.8480917

[7] Kamal, M. S., Islam, M. J., Uddin, M. J., \& Imran, A. Z. M. (2018). Design of a Tri-Band Microstrip Patch Antenna for 5G Application. Int. Conf. Comput. Commun. Chem. Mater. Electron. Eng. IC4ME2 2018, no. 2, 1-3. https://doi.org/10.1109/IC4ME2.2018.8465627

[8] Gerafentis, I. \& Siakavara, K. (2018) Design of ultra wide band slot antennas for future $5 \mathrm{G}$ mobile communication applications. $7^{\text {th }}$ Int. Conf. Mod. Circuits Syst. Technol. MOCAST 2018, 1-4.

[9] Hakanoglu, B. G. \& Turkmen, M. (2017). An inset fed square microstrip patch antenna to improve the return loss characteristics for 5G applications. $32^{\text {nd }}$ Gen. Assem. Sci. Symp. Int. Union Radio Sci. URSI GASS 2017, 1-4. https://doi.org/10.23919/URSIGASS.2017.8104986

[10] Ahmad, F. \& Tlili, B. (2018). Design and analysis of millimeter wave double $F$ slot patch antenna for future $5 \mathrm{G}$ wireless communication. Int. Conf. Electr. Comput. Technol. Appl. ICECTA 2017, 1-4. https://doi.org/10.1109/ICECTA.2017.8252049

[11] Aliakbari, H., Abdipour, A., Costanzo, A., Masotti, D., Mirzavand, R., \& Mousavi, P. (2017). ANN-based design of a versatile millimetre-wave slotted patch multi-antenna configuration for 5G scenarios. IET Microwaves, Antennas Propag., 11(9), 1288-1295. https://doi.org/10.1049/iet-map.2016.0987

[12] Yu, B., Yang, K., Sim, C. Y. D., \& Yang, G. (2018). A Novel $28 \mathrm{GHz}$ Beam Steering Array for 5G Mobile Device with Metallic Casing Application. IEEE Trans. Antennas Propag., 66(1), 462-466. https://doi.org/10.1109/TAP.2017.2772084

[13] Jandi, Y., Gharnati, F., \& Oulad Said, A. (2017). Design of a compact dual bands patch antenna for $5 \mathrm{G}$ applications. Int. Conf. Wirel. Technol. Embed. Intell. Syst. WITS 2017, 1-4. https://doi.org/10.1109/WITS.2017.7934628

[14] El Shorbagy, M., Shubair, R. M., Alhajri, M. I., \& Mallat, N. K. (2017). On the design of millimetre-wave antennas for $5 \mathrm{G}$. Mediterr. Microw. Symp., 7-10. https://doi.org/10.1109/MMS.2016.7803878

[15] Ali, M. M. M. \& Sebak, A. R. (2016). Dual band (28/38 GHz) CPW slot directive antenna for future $5 \mathrm{G}$ cellular applications. IEEE Antennas Propag. Soc. Int. Symp. APSURSI 2016 - Proc., 399-400. https://doi.org/10.1109/APS.2016.7695908

[16] Verma, S., Mahajan, L., Kumar, R., Saini, H. S., \& Kumar, N. (2016), A small microstrip patch antenna for future $5 \mathrm{G}$ applications. $5^{\text {th }}$ Int. Conf. Reliab. Infocom Technol. Optim. ICRITO 2016 Trends Futur. Dir., 460-463. https://doi.org/10.1109/ICRITO.2016.7784999

[17] Saini, J. \& Agarwal, S. K. (2017). Design a single band microstrip patch antenna at $60 \mathrm{GHz}$ millimeter wave for $5 \mathrm{G}$ application. Int. Conf. Comput. Commun. Electron. COMPTELIX 2017, 227-230. 
https://doi.org/10.1109/COMPTELIX.2017.8003969

[18] Sun, W.-J., Yang, W.-W., Chu, P., \& Chen, J.-X. (2019). A wideband stacked dielectric resonator antenna for $5 \mathrm{G}$ applications. Int. J. RF Microw. Comput. Eng., 0(0), e21897. https://doi.org/10.1002/mmce.21897

[19] Huang, D. \& Du, Z. (2019). Compact nine-band antenna for 4G/5G smartphones. Int. J. RF Microw. Comput. Eng., 29(4), e21575. https://doi.org/10.1002/mmce. 21575

[20] Bicer, M. B. \& Akdagli, A. (2012). A Novel Microstrip-Fed Monopole Antenna for WLAN/WiMAX Applications. $J$. Electromagn. Waves Appl., 26(7), 904-913. https://doi.org/10.1080/09205071.2012.710372

[21] Toktas, A., Bicer, M. B., Akdagli, A., \& Kayabasi, A. (2011). Simple formulas for calculating resonant frequencies of $\mathrm{C}$ and $\mathrm{H}$ shaped compact microstrip antennas obtained by using artificial bee colony algorithm. J. Electromagn. Waves Appl., 25(11-12), 1718-1729. https://doi.org/10.1163/156939311797164855

[22] Toktas, A., Bicer, M. B., Kayabasi, A., Ustun, D., Akdagli, A., \& Kurt, K. (2015). A novel and simple expression to accurately calculate the resonant frequency of annular-ring microstrip antennas. Int. J. Microw. Wirel. Technol., 7(6). https://doi.org/10.1017/S1759078714000890

[23] Ustun, D. \& Akdagli, A. (2017). Design of a dual-wideband monopole antenna by artificial bee colony algorithm for UMTS, WLAN, and WiMAX applications. Int. J. Microw. Wirel. Technol., 9(5), 1197-1208. https://doi.org/10.1017/S1759078716001355

[24] Akdağli, A., Biçer, M. B., \& Ermiş, S. (2011). A novel expression for resonant length obtained by using artificial bee colony algorithm in calculating resonant frequency of Cshaped compact microstrip antennas. Turkish J. Electr. Eng. Comput. Sci., 19(4), 597-606.

[25] Kayabasi, A. \& Akdagli, A. (2015). Predicting the Resonant Frequency of E-shaped Compact Microstrip Antennas by Using Anfis and SVM. Wirel. Pers. Commun. https://doi.org/10.1007/s11277-015-2321-6

[26] Akdagli, A. \& Toktas, A. (2010). A novel expression in calculating resonant frequency of h-shaped compact microstrip antennas obtained by using artificial bee colony algorithm. $J$. Electromagn. Waves Appl., 24(14-15), 2049-2061. https://doi.org/10.1163/156939310793675989

[27] Biçer, M. B. \& Akdağl1, A. (2018). Design and Optimization of Amorphous Compact Microstrip Antenna using Artificial Bee Colony Algorithm for Microwave Imaging Applications. in II. International Conference on Engineering Technology and Innovation, p. 137.

[28] Primson, K. P. R. C. \& Anita, R. (2014). Antenna design for WiMAX applications using Artificial Bee Colony Algorithm. J. Theor. Appl. Inf. Technol., 68(3), 493-503.

[29] Chaitanyakumar, M. V. \& Anita, R. (2018). An efficient artificial bee colony algorithm for optimising the design of rectangular microstrip patch antenna. Int. J. Mob. Netw. Des. Innov., 8(1), p. 7. https://doi.org/10.1504//JMNDI.2018.10011189

[30] Yang, Y., Yan, S., Liu, J., \& Liang, J. (2014). Genetic-ant colony optimization algorithm and its application to design of antenna. $10^{\text {th }}$ International Conference on Natural Computation, ICNC 2014. https://doi.org/10.1109/ICNC.2014.6975905

[31] Coleman, C. M., Rothwell, E. J., \& Ross, J. E. (2004). Investigation of simulated annealing, ant-colony optimization, and genetic algorithms for self-structuring antennas. IEEE Trans. Antennas Propag. https://doi.org/10.1109/TAP.2004.825658

[32] Karaboga, N., Güney, K., \& Akdagli, A. (2002). Null steering of linear antenna arrays with use of modified touring ant colony optimization algorithm. Int. J. RF Microw. Comput. Eng. https://doi.org/10.1002/mmce.10034

[33] Toktas, A. (2017). Equivalent Circuit Modelling of an Lshaped Patch Antenna by Optimizing the Lumped Elements Using Differential Evolution Algorithm. Int. J. Intell. Syst. Appl. Eng. https://doi.org/10.18201/ijisae.2017533894

[34] Deb, A., Gupta, B., \& Roy, J. S. (2011). Performance comparison of differential evolution, genetic algorithm and particle swarm optimization in impedance matching of aperture coupled microstrip antennas. in Mediterranean Microwave Symposium. https://doi.org/10.1109/MMS.2011.6068519

[35] Saraereh, O. A., Al Saraira, A. A., Alsafasfeh, Q. H., \& Arfoa, A. (2016). Bio-inspired algorithms applied on microstrip patch antennas: A review. International Journal on Communications Antenna and Propagation. https://doi.org/10.15866/irecap.v6i6.9737

[36] Jian, R., Chen, Y., Cheng, Y.; \& Zhao, Y. (2018). Millimeter Wave Microstrip Antenna Design Based on Swarm Intelligence Algorithm in 5G. IEEE Globecom Work. GC Wkshps 2017 - Proc., vol. 2018-January, 1-6. https://doi.org/10.1109/GLOCOMW.2017.8269196

[37] Akdagli, A. \& Ustun, D. (2018). Bandwidth enhancement of rectangular microstrip antenna with a rectangular slot by using a novel hybrid optimization method based on the $\mathrm{ABC}$ and DE algorithms. Int. J. Numer. Model. Electron. Networks, Devices Fields, 31(5), 1-16. https://doi.org/10.1002/jnm.2345

[38] Jian, R., Chen, Y., \& Chen, T. (2019). Multi-Parameters Unified-Optimization for Millimeter Wave Microstrip Antenna Based on ICACO. IEEE Access, 7, 53012-53017. https://doi.org/10.1109/ACCESS.2019.2912461

[39] Balanis, C. A. (2016). Antenna Theory: Analysis and Design. Wiley \& Sons, Inc.

[40] Schneider, M. V. (1969). Microstrip Lines for Microwave Integrated Circuits. Bell Syst. Tech. J. https://doi.org/10.1002/j.1538-7305.1969.tb04274.x

[41] Civicioglu, P. (2013). Artificial cooperative search algorithm for numerical optimization problems. Inf. Sci. (Ny)., 229, 5876. https://doi.org/10.1016/j.ins.2012.11.013

\author{
Authors' contacts: \\ Mustafa Berkan Biçer, Asst. Prof. Dr. \\ Izmir Bakircay University, \\ Engineering and Architecture Faculty, \\ Electrical and Electronics Engineering Department, \\ 35660, Menemen, Izmir, Turkey \\ mustafa.bicer@bakircay.edu.tr
}

